\title{
Research and proposal the configuration of the booster circuit in the grid connected solar cell system and MPPT simulation in the partially shaded conditions
}

\author{
Minh Duc Nguyen ${ }^{1,}{ }^{*}$, Anh Viet Truong ${ }^{2}$, Phi Hoang Le ${ }^{2}$, Lan Thuy Thi Vu ${ }^{3}$, Y Nhu \\ Do ${ }^{4}$, Chuong Trong Trinh 5 \\ ${ }^{1}$ Institute of Energy Science - VAST, Hanoi, Vietnam \\ ${ }^{2}$ HCMC University of Technology and Educatio, Ho Chi Minh Gity, Vietnam \\ ${ }^{3}$ Thai Binh University, Thai Binh,Vietnam \\ ${ }^{4}$ Hanoi University of Mining and Geology, Hanoi, Vietnam \\ ${ }^{5}$ Hanoi University of Industry, Hanoi, Vietnam
}

\begin{tabular}{|c|c|}
\hline ARTICLE INFO & ABSTRACT \\
\hline $\begin{array}{l}\text { Article history: } \\
\text { Received } 25^{\text {th }} \text { Mar. } 2021 \\
\text { Revised } 02^{\text {nd }} \text { July } 2021 \\
\text { Accepted } 29^{\text {th }} \text { July } 2021\end{array}$ & $\begin{array}{l}\text { This paper proposes a new turbocharger configuration that uses fewer } \\
\text { semiconductor locks, fewer reactor coils, and a higher turbidity factor } \\
\text { than conventional turbocharger configurations. This allows for easier } \\
\text { control, less component loss, high efficiency, reduced circuit size and }\end{array}$ \\
\hline $\begin{array}{l}\text { Keywords: } \\
\text { DC/DC, } \\
\text { GA, } \\
\text { MPPT, } \\
\text { PV, } \\
\text { P\&O. }\end{array}$ & $\begin{array}{l}\text { weight, and low cost. A booster circuit configuration with recommended } \\
\text { neutral is required and is suitable for T-shaped and NPC } 3 \text {-orderinverters. } \\
\text { In addition, the article also applies the maximum power point tracking } \\
\text { algorithm for PV systems working in partially shaded conditions to } \\
\text { improve the working efficiency of PV systems, to meet the requirements of } \\
\text { the PV systems. grid-connected large capacity PV system. }\end{array}$ \\
\hline
\end{tabular}

Copyright $@ 2021$ Hanoi University of Mining and Geology. All rights reserved.

${ }^{*}$ Corresponding author

E - mail: minhnguyenduc.ies@gmail.com

DOI: 10.46326/JMES.2021.62(4).09 


\title{
Tạp chí Khoa học Kỹ thuật Mỏ - Địa chất
}

Trang điện tử: http://tapchi.humg.edu.vn

\section{Nghiên cứu, đề xuất cấu hình mạch tăng áp trong hệ thống pin mặt trời kết nối lưới điện và mô phỏng MPPT trong điều kiện có bóng che từng phần}

\author{
Nguyễn Đức Minh ${ }^{1,}{ }^{*}$, Trương Việt Anh ${ }^{2}$, Lê Hoàng Phi ${ }^{2}$, Vũ Thị Thùy Lan ${ }^{3}$, Đỗ Như \\ Ý $^{4}$, Trịnh Trọng Chưởng ${ }^{5}$
}

1 Viện Khoa học Năng lượng -VAST, Hà Nội, Việt Nam

${ }^{2}$ Trường Đại học Sư phạm Kỹ thuật Tp. Hồ Chí Minh, TP. Hồ Chí Minh, Việt Nam

${ }^{3}$ Trưòng Đại học Thái Bình, Thái Bình, Việt Nam

${ }^{4}$ Trường Đại học Mỏ - Địa chất, Hà Nội, Việt Nam

${ }^{5}$ Trường Đại học Công nghiệp Hà Nội, Hà Nội, Việt Nam

\section{THÔNG TIN BÀI BÁO T TÓM TẮT}

\section{Quá trình:}

Nhận bài 25/3/2021

Sưa xong 02/7/2021

Chap nhận đăng 29/7/2021

\section{Tù̀ khóa:}

DC/DC

Dò tìm điểm công suất

cực đại,

GA,

PV,

$\mathrm{P} \& O$.
Bài báo này đề xuất một cấu hình tăng áp mới sử dụng ít khóa bán dẫn, ít cuộn kháng và hệ số tăng áp cao hơn các cấu hình tăng áp thông thường. Điều này cho phép việc điểu khiển dễ dàng hơn, ít tổn thất trên linh kiện, hiệu suất cao, giảm kích thước và trọng lương mạch, chi phí thấp. Cấu hình mạch tăng áp có trung tính đề xuất cần thiết và phù hợp với các bộ nghịch lưu 3 bậc hình T và NPC. Ngoài ra, bài báo cũng áp dụng giải thuật dò điểm công suất cực đại cho hệ thống PV làm việc trong điều kiện có bóng che một phần đểnâng cao hiệu quả của làm việc của hệ thống $P V$, đáp úng yêu cầu của các hệ thống PV công suất lớn nối lưới.

C 2021 Trường Đại học Mỏ - Địa chất. Tất cả các quyền được bảo đảm.

\section{Mở đầu}

Các bộ chuyển đổi tăng áp DC/DC được sử dụng như một thiết bị trung gian để biến đổi năng lượng giữa các nguồn điện áp thấp tới mức điện áp DC cao hơn. Trong nhiều ứng dụng hiện đại, chẳng hạn hệ thống PV được kết nối lưới (Figueres và nnk., 2009) và các hệ thống phát điện dùng

\footnotetext{
*Tác giả liên hệ

E - mail: minhnguyenduc.ies@gmail.com

DOI: 10.46326/JMES.2021.62(4).09
}

năng lượng tái tạo, cần thiết phải sử dụng bộ chuyển đổi với hệ số tăng áp cao. Các bộ chuyển đổi tăng áp DC/DC khác nhau đã được trình bày trong các tài liệu (Deshpande và Bhasme, 2018; Selvaraj và Rahim, 2009; Scarpa và Buso, 2009;Li và nnk., 2007). Tùy vào ứng dụng, chúng có cấu trúc cách ly (Sahoo và Kumar, 2014) hoặc không cách ly (Chen và nnk., 2013). Các bộ chuyển đổi sử dụng biến áp có thể thu được hệ số tăng áp cao bằng cách điều chỉnh tỷ số vòng dây và sử dụng 
các linh kiện có giá trị định mức thấp để giảm tổn thất dẫn. Tuy nhiên, các điện cảm rò gây ra gai điện áp cao trên các linh kiện công suất và thường đòi hỏi một mạch dập xung (snubber). Có thể sử dụng mạch dập xung kiểu điện trở - tụ điện - diode (RCD) hoặc mạch kẹp để triệt tiêu năng lượng rò rỉ (Marabeas và nnk., 2011; Das và Pradhan, 2011; A. Khan và Pal, 2017; Kumari và $\mathrm{Babu,} \mathrm{2013;}$ Armstrong và nnk., 2006).

Để giải quyết bài toán về mật độ công suất và hệ số tăng áp cao trong các bộ chuyển đổi DC/DC, các nhà nghiên cứu và nhà sản xuất đã giải quyết theo hai cách khác nhau: phát triển công nghệ bán dẫn và đề xuất các cấu hình mới. Tuy nhiên, để thiết kế một bộ chuyển đổi nhỏ gọn, phải có cách để giảm thiểu hoặc loại bỏ các tổn thất chuyển mạch. Các kỹ thuật chuyển mạch mềm và cộng hưởng được áp dụng cho các bộ tăng áp cao để giảm thiểu tổn thất chuyển mạch. Bài báo này trình bày đề xuất cấu hình tăng áp DC/DC mới phù hợp hơn, bằng cách sử dụng một cấu hình tăng áp mới sử dụng ít khóa bán dẫn, ít cuộn kháng và hệ số tăng áp cao hơn các cấu hình tăng áp thông thường. Từ đó dẫn đến việc điều khiển dễ dàng hơn, ít tổn thất trên linh kiện, hiệu suất cao, giảm kích thước và trọng lượng mạch, chi phí thấp. Cấu hình mạch tăng áp có trung tính đề xuất cần thiết và phù hợp với các bộ nghịch lưu 3 bậc hình $T$ và NPC (Neutral Point Clamped- Kẹp điểm trung tính). Kết quả đánh giá hiệu quả của mạch được phân tích bởi thuật toán GA khi đánh giá quá trình dò tìm điểm công suất cực đại (MPPT) trong điều kiện có bóng che từng phần.

\section{Cấu trúc hệ thống}

\subsection{Cấu hình mạch tăng áp $D C / D C$ đề xuất}

Hình 1 chỉ ra cấu hình mạch tăng áp DC/DC đề xuất, gồm một nguồn cung cấp DC (Vin)- nguồn Pin quang điện, một khóa bán dẫn chuyển mạch $(S)$, ba diode $\left(D_{1}, D_{2}, D_{3}\right)$, một cuộn cảm $(L)$, ba tụ điện $\left(\mathrm{C}_{1}, \mathrm{C}_{2}, \mathrm{C}_{3}\right)$. Đầu ra được nối với tải trở (Rload). Giá trị điện áp đầu ra Vo tăng cao nhờ hoạt động của khóa bán dẫn $S$ và khả năng tích trữ năng lượng của cuộn dây $\mathrm{L}$ và tụ điện $\mathrm{C} 3$ làm cho điện áp trên tụ $\mathrm{C}_{1}$ và $\mathrm{C}_{2}$ cao hơn điện áp nguồn cấp.

\subsection{Phương pháp điều khiển}

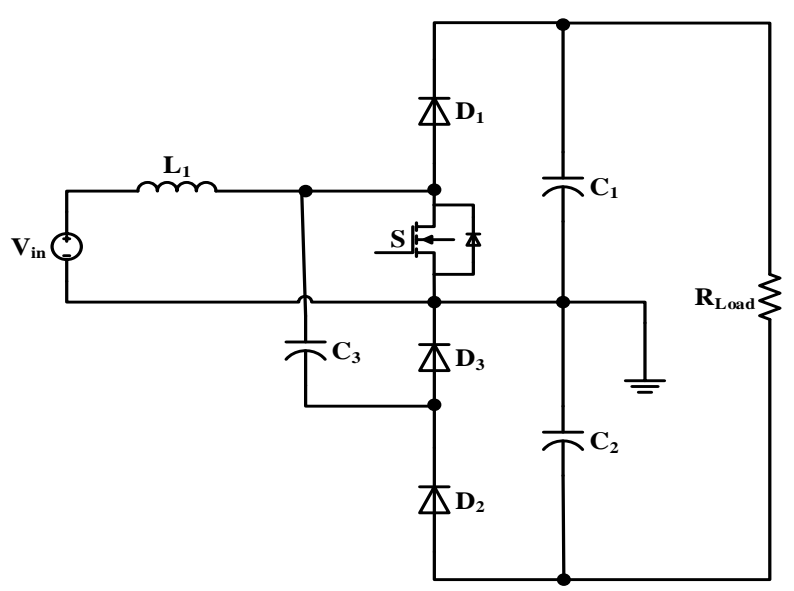

Hình 1. Cấu hình mạch tăng áp $D C / D C$ đề xuất.

Phương pháp điều khiển dựa trên phương pháp điều chế độ rộng xung PWM - phương pháp điều chế dựa trên sự thay đổi độ rộng của chuỗi xung vuông dẫn đến sự thay đổi điện áp ra. Các PWM khi biến đổi thì có cùng một tần số và khác nhau về độ rộng của sườn dương hay hoặc sườn âm. Xung PWM được tạo ra bằng cách so sánh điện áp điều khiển UX với sóng mang là xung tam giác với tần số $\mathrm{f}$, biên độ đỉnh - đỉnh là 1 (Hình 2). Ở đây: TON là thời gian đóng khóa bán dẫn S, T-TON
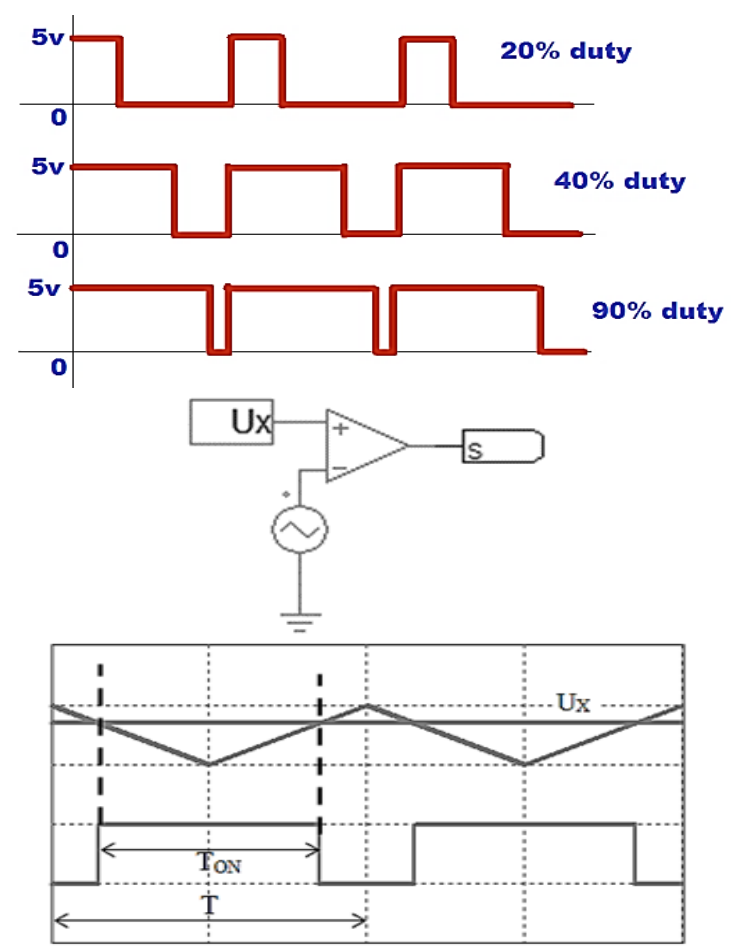

Hình 2. Giản đồ điều chế độ rộng xung và kỹ thuật điều chế PWM. 
là thời gian mở khóa. Do đó hệ số chu kỳ có giá trị là: $\mathrm{D}=\mathrm{TON} / \mathrm{T}$.

\subsection{Nguyên lý hoạt động}

Cấu hình này giải quyết các yêu cầu: hệ số tăng áp lớn, số linh kiện chuyển mạch tích cực (khóa bán dẫn S) ít, tạo ra điện áp DC đối xứng qua điểm trung tính. Cấu hình tăng áp này hoạt động dựa trên hai trạng thái đóng mở khóa bán dẫn $\mathrm{S}$ (Hình 3).

Trạng thái 1: trong khoảng thời gian $\mathrm{t}=\mathrm{T}$ TON, khóa $\mathrm{S}$ mở (hở mạch), lúc này năng lượng trên nguồn và năng lượng trên cuộn kháng L sẽ được nạp qua các tụ $\mathrm{C}_{1}$ và $\mathrm{C}_{3}$ thông qua các diode $D_{1}$ và $D_{3}$. Điện áp trên tụ được xác định theo công thức (1):

Trạng thái 1: trong khoảng thời gian $\mathrm{t}=\mathrm{T}$ TON, khóa $\mathrm{S}$ mở (hở mạch), lúc này năng lượng trên nguồn và năng lượng trên cuộn kháng $L$ sẽ được nạp qua các tụ $\mathrm{C}_{1}$ và $\mathrm{C}_{3}$ thông qua các diode $\mathrm{D}_{1}$ và $\mathrm{D}_{3}$. Điện áp trên tụ được xác định theo công thức (1):

$$
U_{c 1}=U_{c 3}=U \frac{T}{T-T_{O N}}
$$

Trong đó: $U_{c 1}$ - điện áp trên tụ $C_{1},(\mathrm{~V}) ; U_{c 3}$ - điện áp trên tụ $C_{3},(\mathrm{~V}) ; U$ - điện áp nguồn cấp $\mathrm{DC},(\mathrm{V}) ; T$ - chu kỳ chuyển mạch, $(\mathrm{s}), T_{O N}$ - thời gian đóng khóa bán dẫn $\mathrm{S},(\mathrm{s})$.

Trạng thái 2: trong khoảng thời gian TON, khóa $S$ đóng (ngắn mạch). Lúc đó năng lượng từ

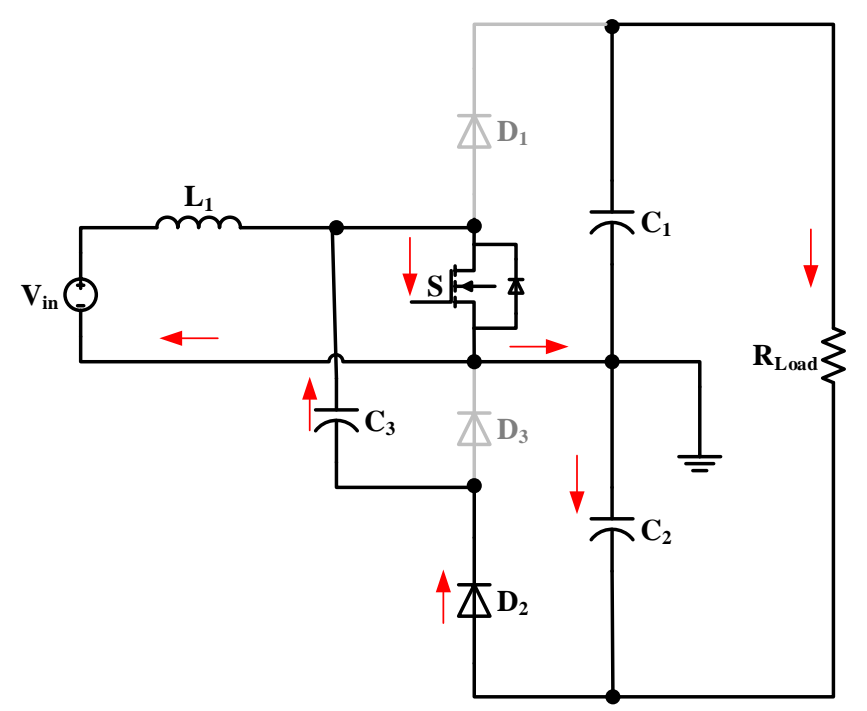

Hình 3. Các chế độ hoạt động của cấu hình đề xuất. nguồn một chiều sẽ tích trũ vào cuộn kháng L. Đồng thời trong trạng thái này khóa $\mathrm{S}$ và $\mathrm{D}_{2}$ đóng nên điện áp từ tụ $C_{3}$ sẽ nạp qua tụ $C_{2}$. Điện áp trên tụ $\mathrm{C}_{2}$ có giá trị bằng điện áp trên tụ $\mathrm{C}_{3}$. Do đó:

$$
U_{c 2}=U_{c 3}=U \frac{T}{T-T_{O N}}
$$

Trong đó: $U_{c 2}$ - điện áp trên tụ $C_{2},(\mathrm{~V})$.

Thay (2) vào (1) có thể xác định điện áp trên tụ C1 và $C 2$ như (3), (4):

$$
\begin{aligned}
& U_{c 1}=U \frac{1}{1-D} \\
& U_{c 2}=U \frac{1}{1-D}
\end{aligned}
$$

Trong đó: D - hệ số chu kỳ.

Kết quả là có điện áp trên 2 tụ mắc nối tiếp $\mathrm{C} 1$ và $\mathrm{C} 2$ bằng nhau và đối xứng. Do đó điện áp trên tải có giá trị:

$$
U_{\text {Load }}=U_{c 1}+U_{c 2}=2 U_{c 2}=2 \frac{1}{1-D} U
$$

Trong đó: $U_{\text {Load }}$ - điện áp trên tải, (V).

Và điểm trung tính chính là nơi nối tụ C1, C2 cũng chính là mass nguồn. Hệ số tăng áp của mạch:

$$
k_{B}=\frac{2}{1-D}
$$

Trong đó: $k_{B}$ - hệ số tăng áp.

Như vậy, cấu hình mạch tăng áp đề xuất chỉ sử dụng một khóa bán dẫn chuyển mạch S. Bên cạnh đó cấu hình cho hệ số nhân áp cao nhưng điện áp trên các tụ $\mathrm{C}_{1}, \mathrm{C}_{2}, \mathrm{C}_{3}$ và điện áp phục hồi ngược trên các diode $\mathrm{D}_{1}, \mathrm{D}_{2}, \mathrm{D}_{3}$ chỉ bằng một nửa so với điện áp đầu ra. Do đó, có thể sử dụng diodeSchottky có giá thành thấp và giảm thiểu các tổn thất liên quan đến việc phục hồi ngược diode, một trong các tổn thất chính trong các ứng dụng tăng áp có hệ số tăng áp lớn.

\subsection{Thông số kỹ thuật đầu vào}

Để lựa chọn các linh kiện cho mạch, cần xác định yêu cầu kỹ thuật của mạch, gồm các thông số sau:

- Khoảng điện áp vào có các trị số sau:

+ Điện áp danh định là điện áp của tấm pin tại điểm có công suất cực đại: $\mathrm{V}_{\mathrm{N}}=52 \mathrm{~V}$.

+ Điện áp lớn nhất: lấy bằng điện áp hở mạch của tấm pin: $\mathrm{V}_{\text {imax }}=65 \mathrm{~V}$. 
+ Điện áp cực tiểu: là điện áp tối thiểu để Arduino điều khiển đóng ngắt cho MOSFET: $V_{\text {imin }}$ $=15 \mathrm{~V}$.

- Điện áp định mức đầu ra: là điện áp đầu ra tại điểm có công suất cực đại khi không có bóng che, $\mathrm{V}_{\mathrm{ON}}=165 \mathrm{~V}$.

- Dòng tải lớn nhất: $\mathrm{I}_{\mathrm{Omax}}=\mathrm{V}_{\mathrm{ON}} / \mathrm{R}_{\mathrm{L}}=165 / 154$ $=1,1 \mathrm{~A}$.

- Độ rộng xung tối đa: đảm bảo không vượt quá khả năng chịu đựng của các khóa bán dẫn, $\mathrm{D}_{\max }=80 \%$.

- Tần số đóng cắt: tần số cao giúp giảm yêu cầu về linh kiện nhưng đồng thời làm giảm hiệu suất mạch, $\mathrm{f}_{\mathrm{S}}=40 \mathrm{kHz}$.

- Các loại mạch tích hợp: gồm các cảm biến, mạch xử lý tín hiệu phục vụ cho việc điều khiển MPPT.

Mạch thực nghiệm cấu hình tăng áp đề xuất được điều khiển bởi board Arduino UNO R3. Mạch tăng áp đề xuất được xây dựng với một Mosfet công suất kết hợp với mạch kích để điều khiển, 3 diode xung, 3 tụ điện phân cực được sử dụng để lưu năng lượng tạm thời trong mạch và cuộn cảm, sơ đồ khối mô hình thực nghiệm được thể như Hình 4.

- Để khảo sát giải thuật và mô hình một cách chính xác nhất, thay vì sử dụng pin quang điện thực tế rất khó cho việc xác định đặc tuyến của tấm pin khi bức xạ mặt trời hay nhiệt độ thay đổi, nghiên cứu này sử dụng bộ mô phỏng Pin quang điện Chroma 62050H. Bộ mô phỏng này có ưu điểm là có thể tùy chỉnh đầu ra theo thông số của tấm pin dưới rất nhiều điều kiện khác nhau như bức xạ, nhiệt độ thay đổi, hiện tượng bóng che,... đồng thời có thể ghi lại dữ liệu và kiểm tra hiệu suất của giải thuật tìm điểm MPPT. Các dữ liệu đều có thể giám sát trên máy tính thông qua phần mềm giao tiếp Chroma Array Simulation. Các thông số của bộ mô phỏng pin quang điện được thể hiện trong Bảng 1.

Mạch tăng áp DC/DC đề xuất gồm: một mạch tăng áp truyền thống và một bộ nhân điện áp.

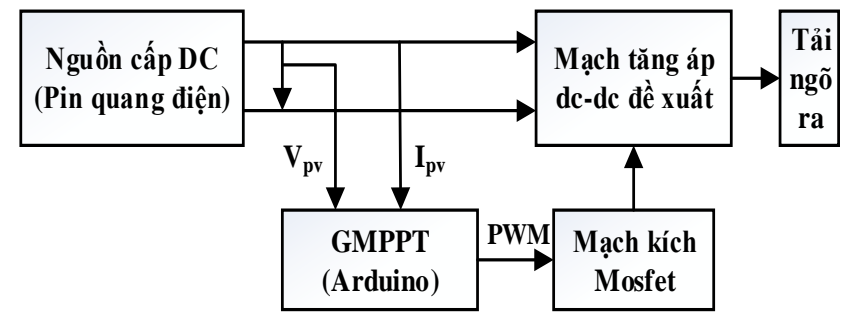

Hình 4. Sơ đồ khối mô hình thực nghiệm.

Mạch đo lường gồm có mạch đo áp dùng cầu phân áp và mạch đo dòng điện dùng cảm biến ACS712 để đo dòng điện và điện áp đầu vào, tín hiệu này được kết nối với đầu vào tương tự của board Arduino.

Mạch kích Mosfet dùng Opto TLP250 để nhận tín hiệu xung PWM từ board Arduino để kích cho Mosfet đóng ngắt, sơ đồ nguyên lý bộ tăng áp DC/DC dò MPPT thể hiện như Hình 5.

- Để Khảo sát cấu hình mạch tăng áp đề xuất với nguồn pin quang điện và dò MPPT thông số đầu vào: Sơ đồ nguyên lý mô phỏng cấu hình tăng áp đề xuất dò điểm công suất cực đại trên phần mềm PSIM thể hiện ở Hình 6. Trong mô hình mô phỏng sử dụng 3 module $\mathrm{PV}$ mắc nối tiếp để thuận tiện cho việc khảo sát hiện tượng bóng che. Đầu ra của dãy $\mathrm{PV}$ được mắc với đầu vào của cấu hình tăng áp đề xuất. Có các cảm biến dòng điện và điện áp để thu thập tín hiệu dòng điện, điện áp đầu vào truyền về Arduino, từ đó Arduino xuất tín hiệu xung PWM để điều khiển đóng ngắt Mosfet với hệ số chu kỳ (D) thay đổi. Hai giải thuật GA và $P \& O$ được đề xuất áp dụng để so sánh, đánh giá. Thí nghiệm mô phỏng được tiến hành trên sơ đồ này. Các thông số của module PV được thể hiện trong Bảng 2. Thông số của các linh kiện sử dụng trong mô phỏng và thực nghiệm được trình bày trong Bảng 3.

Phần mềm PSIM được sử dụng để khảo sát cấu hình tăng áp đề xuất với giải thuật dò điểm MPPT bằng GA và $\mathrm{P} \& 0$ cho hệ thống pin quang điện làm việc trong điều kiện bức xạ đồng nhất và

Bảng 1. Các thông số của bộ mô phỏng pin quang điện.

\begin{tabular}{|l|l|l|l|}
\hline \multicolumn{1}{|c|}{ Thông số } & \multicolumn{1}{|c|}{ Giá trị } & \multicolumn{1}{c|}{ Thông số } & \multicolumn{1}{c|}{ Giá trị } \\
\hline Điện áp ra & $0-600 \mathrm{~V}$ & Tầm đo dòng điện & $3.4 \mathrm{~A} / 8.5 \mathrm{~A}$ \\
\hline Dòng điện định mức & $0-8.5 \mathrm{~A}$ & Nhiễu điện áp đỉnh-đỉnh) & $1.5 \mathrm{~V}$ \\
\hline Công suất định mức & $5 \mathrm{~kW}$ & Độ dập điện áp hiệu dụng & $650 \mathrm{mV}$ \\
\hline Tầm đo điện áp & $120 \mathrm{~V} / 600 \mathrm{~V}$ & Độ dập dòng điện hiệu dụng & $150 \mathrm{~mA}$ \\
\hline
\end{tabular}




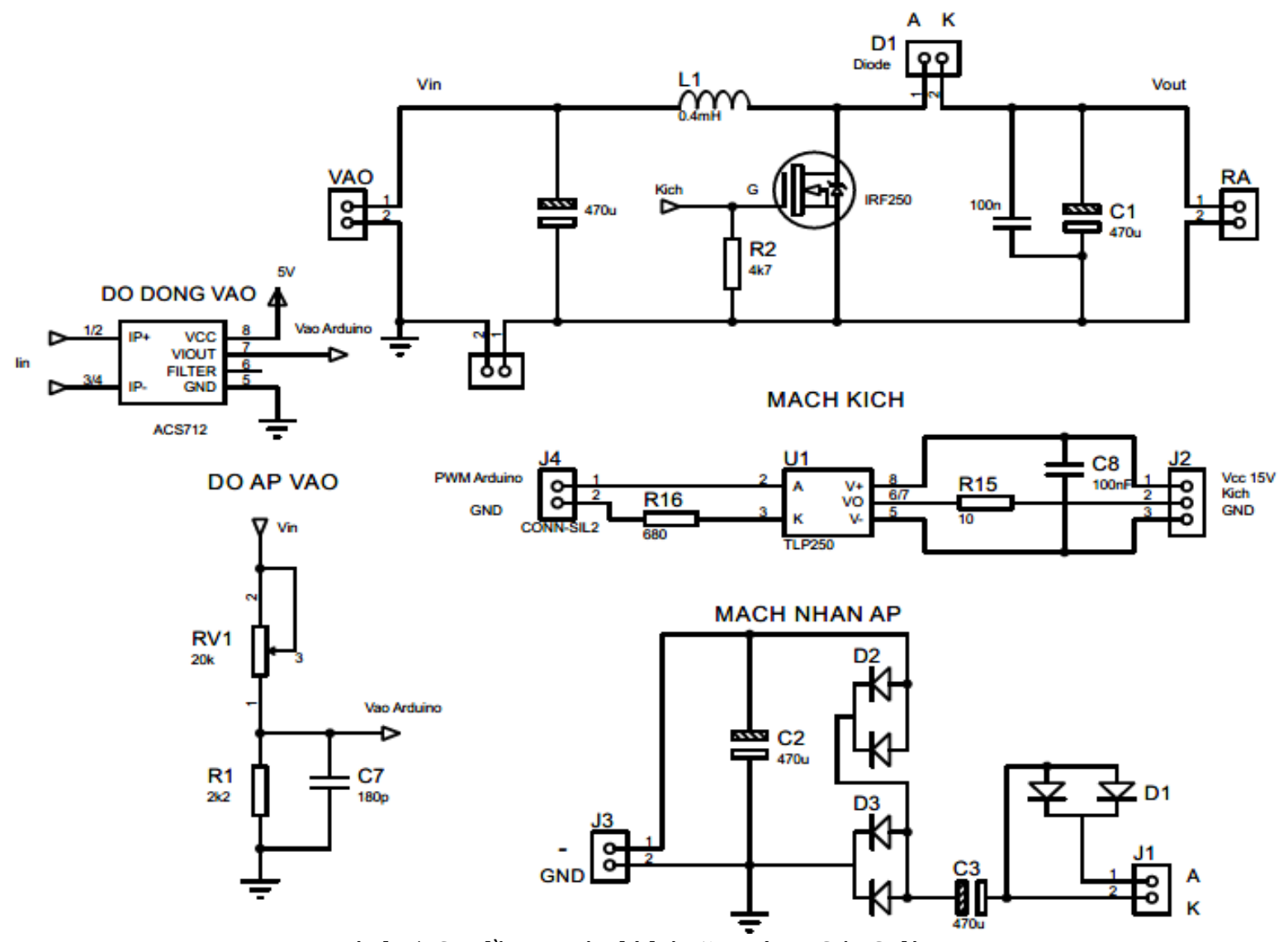

Hình 5. Sơ đồ nguyên lý bộ tăng áp $D C / D C$ dò $M P P T$.

Bảng 2. Thông số tấm pin quang điện dùng trong mô phỏng và thực nghiệm.

\begin{tabular}{|l|l|}
\hline Số lượng cell & 36 \\
\hline Công suất cực đại $\left(\mathrm{P}_{\max }\right)$ & $60 \mathrm{~W}$ \\
\hline Dòng điện tại $\mathrm{P}_{\max }\left(\mathrm{I}_{\mathrm{mp}}\right)$ & $3,33 \mathrm{~A}$ \\
\hline Điện áp tại $\mathrm{P}_{\max }\left(\mathrm{V}_{\mathrm{mp}}\right)$ & $18 \mathrm{~V}$ \\
\hline Dòng điện ngắn mạch $\left(\mathrm{I}_{\mathrm{sc}}\right)$ & $3,99 \mathrm{~V}$ \\
\hline Điện áp hở mạch $\left(\mathrm{V}_{\mathrm{oc}}\right)$ & $21,6 \mathrm{~V}$ \\
\hline Hiệu suất module & $14,2 \%$ \\
\hline Điện áp cực đại của hệ thống & $600 \mathrm{~V}$ \\
\hline Kích thước & $780 \times 675 \times 35 \mathrm{~mm}$ \\
\hline
\end{tabular}

Bảng 3. Thông số các linh kiện sử dụng trong mô phỏng và thực nghiệm.

\begin{tabular}{|l|l|l|}
\hline \multicolumn{2}{|l|}{ Thông số } & Giá trị \\
\hline Cuộn dây & $\mathrm{L}$ & $0,4 \mathrm{mH}$ \\
\hline Diode & $\mathrm{D}_{1}, \mathrm{D}_{2}, \mathrm{D}_{3}$ & MUR1660CT \\
\hline \multirow{2}{*}{ Tụ điện } & $\mathrm{C}_{1}, \mathrm{C}_{2}, \mathrm{C}_{3}$ & $470 \mu \mathrm{F} / 250 \mathrm{~V}$ \\
\cline { 2 - 3 } & $\mathrm{C}_{\text {in }}$ & $470 \mu \mathrm{F} / 100 \mathrm{~V}$ \\
\hline Khóa bán dẫn & $\mathrm{S}$ & IRFP250N \\
\hline \multicolumn{2}{|l}{ Tần số chuyển mạch $\left(\mathrm{f}_{\mathrm{s}}\right)$} & $40 \mathrm{kHz}$ \\
\hline
\end{tabular}

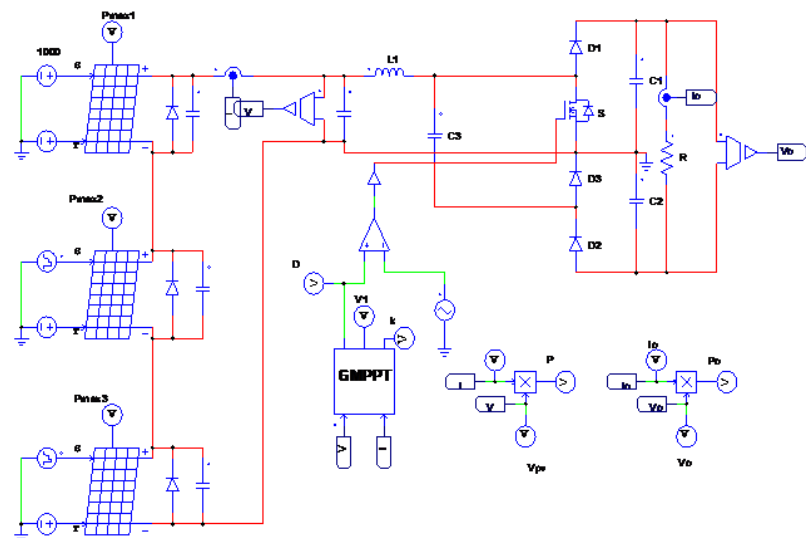

Hình 6. Cấu hình mạch tăng áp đề xuất dò MPPT trên PSIM.

có bóng che một phần. Trong phạm vi bài báo, nhóm nghiên cứu đã khảo sát hệ thống pin quang điện làm việc trong 4 trường hợp có các mức bức xạ khác nhau, nhiệt độ môi trường $\left(25^{\circ} \mathrm{C}\right)$ và tải không thay đổi. 


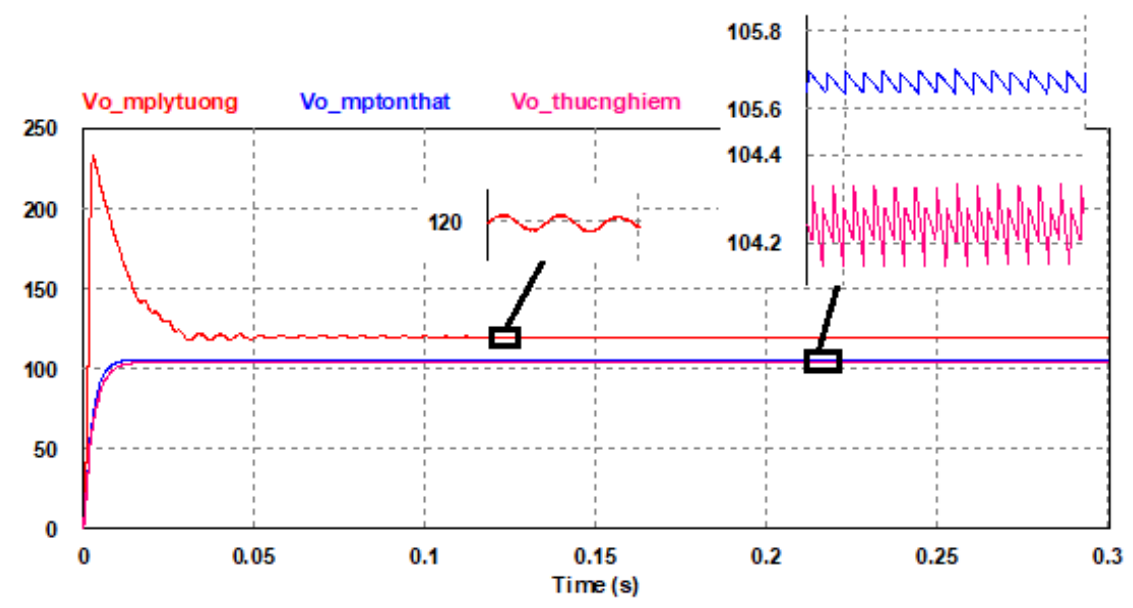

Hình 7. Dạng sóng điện áp đầu ra $V_{o}$ của cấu hình tăng áp.

\subsection{Kết quả và thảo luận}

2.5.1. Cấu hình mạch tăng áp đề xuất với nguồn một chiều cố định

Hình 7 là dạng sóng điện áp đầu ra của cấu hình tăng áp đề xuất. Với hệ số chu kỳ $\mathrm{D}=0,5$, Vin $=30 \mathrm{~V}, \mathrm{R}=80 \Omega$ ở điều kiện lý tưởng không xét đến tổn thất năng lượng trong bộ chuyển đổi, giá điện áp đầu ra mô phỏng là $V_{0}=120 \mathrm{~V}$ thể hiện qua đường màu đỏ. Ở điều kiện có xét đến tổn thất năng lượng thì giá trị điện áp đầu ra mô phỏng là $\mathrm{V}_{0}=105,65 \mathrm{~V}$ thể hiện qua đường màu xanh dương. Giá trị điện áp đầu ra thực nghiệm là $\mathrm{V}_{0}=$ $104,25 \mathrm{~V}$ thể hiện qua đường màu hồng.

2.5.2. Khảo sát mạch tăng áp đề xuất với nguồn một chiều cố định ở nhiều hệ số chu kỳ (D) và tần số chuyển mạch $\left(f_{s}\right)$ khác nhau để so sánh hiệu suất giữa mô phỏng và thực nghiệm

Kết quả so sánh hiệu suất mô phỏng và thực nghiệm của cấu hình đề xuất với điện áp đầu vào $\mathrm{V}_{\text {in }}=50 \mathrm{~V}$, hệ số chu kỳ $\mathrm{D}=0,5$ được trình bày ở Hình 8. Hiệu suất đo được ở các mức tải khác nhau dưới tần số chuyển mạch khác nhau. Hiệu suất

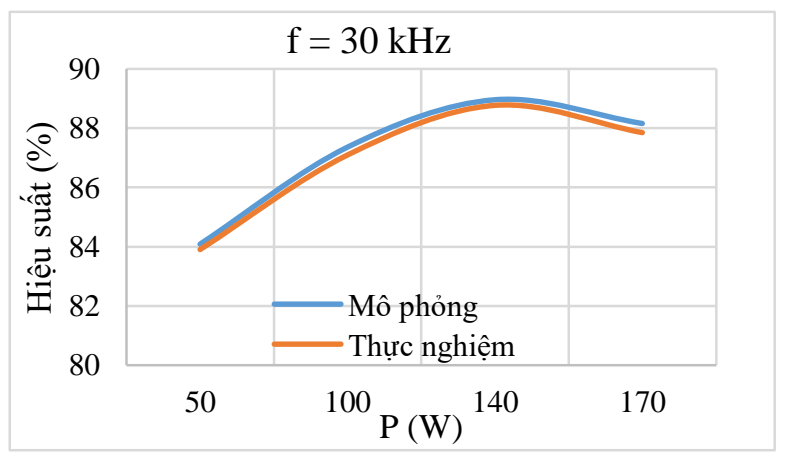

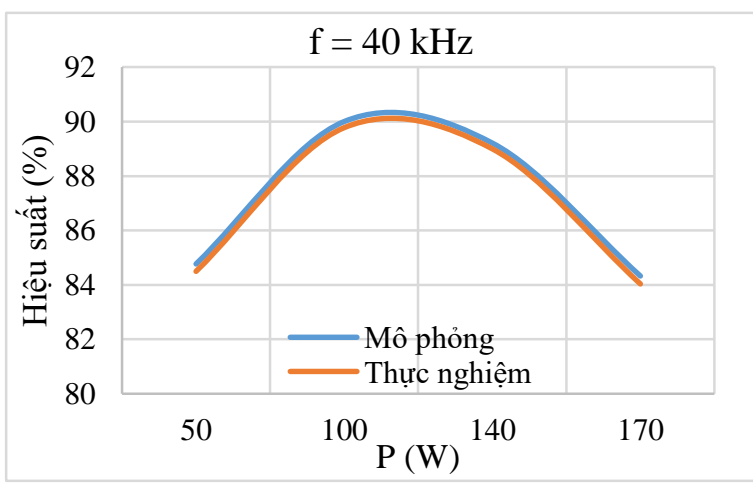
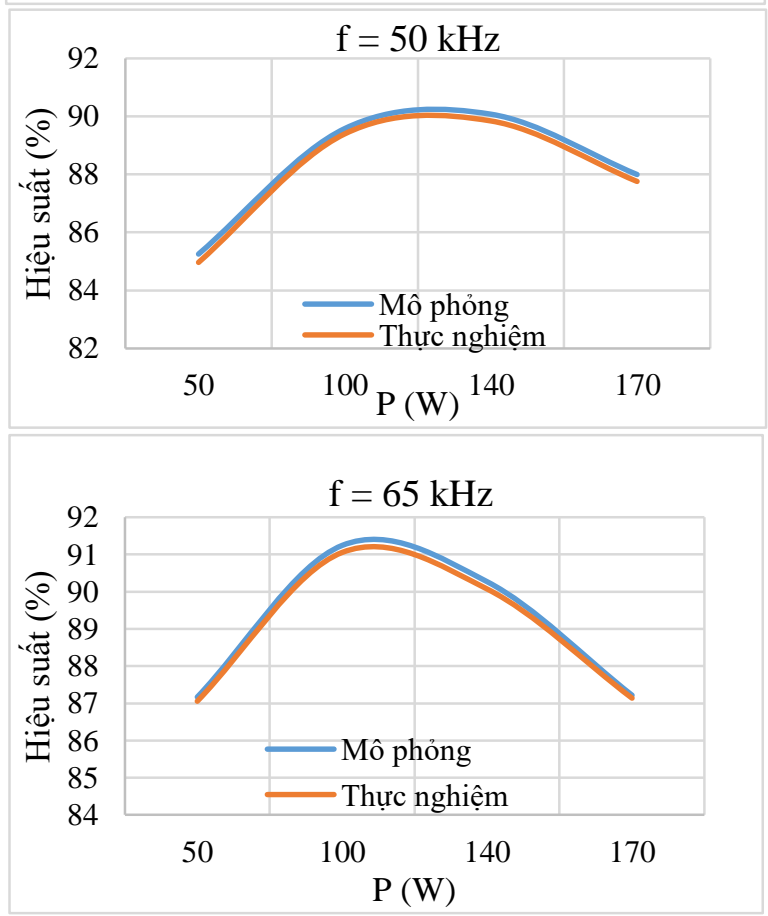

Hình 8. So sánh hiệu suất mô phỏng và thực nghiệm của cấu hình theo $f_{s}$. 
thực nghiệm cao nhất của bộ chuyển đổi là 91,5\% ở tần số chuyển mạch $\mathrm{f}=65 \mathrm{kHz}$. Do đó, với tần số chuyển mạch $\mathrm{f}=65 \mathrm{kHz}$, điện áp đầu vào $\mathrm{V}_{\text {in }}=30$ $\mathrm{V}$, hiệu suất mô phỏng và thực nghiệm đo được ở các mức tải khác nhau dưới các hệ số chu kỳ (D) khác nhau được thể hiện ở Hình 9 . Hiệu suất thực nghiệm cao nhất đo được là $91 \%$ ở hệ số chu kỳ D $=0,35$. Nhìn chung, kết quả điện áp đầu ra, hiệu suất giữa mô phỏng và thực nghiệm có sự chênh lệch là do tổn thất năng lượng trên các linh kiện, đặc biệt là điện trở nối tiếp tụ điện ESR mà trên phần mềm mô phỏng không thể mô tả chính xác được (không có thiết bị hỗ trợ nên không thể xác định được chính xác điện trở nối tiếp tụ điện ESR).
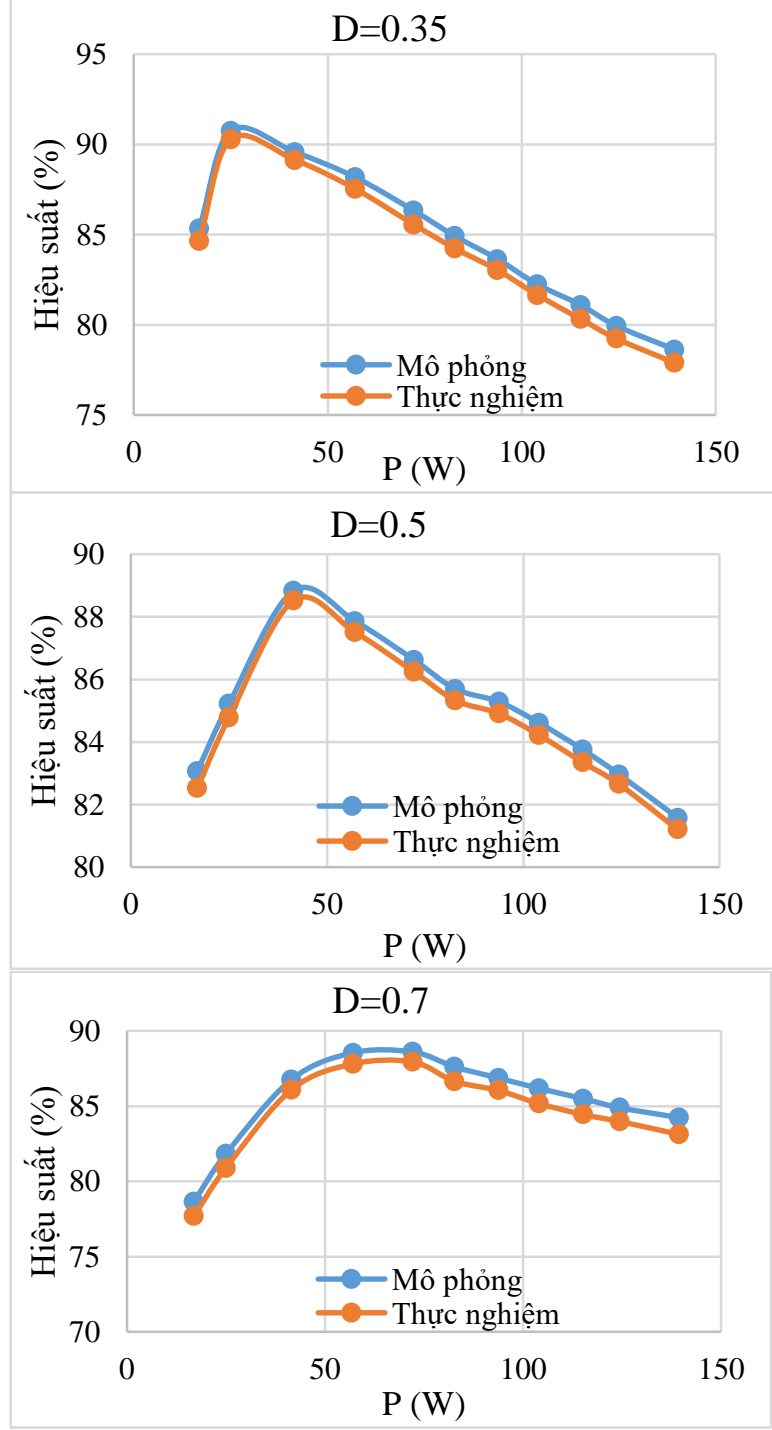

Hình 9. So sánh hiệu suất mô phỏng và thực nghiệm của cấu hình đề xuất theo hệ số chu kỳ (D).
2.5.3. Cấu hình mạch tăng áp đề xuất với nguồn pin quang điện và dò MPPT

Trường hợp 1: Các tấm pin nhận mức bức xạ đồng đều như nhau, không có bóng che 1.000 $1.000-1.000 \mathrm{~W} / \mathrm{m}^{2}$.

Hình 10 thể hiện đặc tuyến $\mathrm{P}-\mathrm{V}$ của hệ thống pin quang điện với mức bức xạ $1.000 \mathrm{~W} / \mathrm{m}^{2}$ ở mỗi module, do đó đặc tuyến chỉ có một đỉnh duy nhất và có công suất là 190,87 W. Hình 11 lần lượt thể hiện điểm công suất mà giải thuật $P \& O$ và $G A$ dò được chạy trên cấu hình tăng áp đề xuất. Nhận thấy rằng 2 giải thuật đều dò ra được điểm có công suất cực đại.

Trường hợp 2: Các tấm pin có mức bức xạ lần lượt là $1.000-800-600 \mathrm{~W} / \mathrm{m}^{2}$ (điểm cực đại toàn cục nằm bên phải).

Hình 12 thể hiện đặc tuyến $\mathrm{P}-\mathrm{V}$ của hệ thống pin quang điện với mức bức xạ lần lượt trên các module là $1.000-800-600 \mathrm{~W} / \mathrm{m}^{2}$, do đó đặc tuyến có 3 đỉnh công suất cực đại nhưng đỉnh có công suất lớn nhất là $127,47 \mathrm{~W}$ nằm ở phía bên phải. Hình 13 lần lượt thể hiện điểm công suất mà giải thuật $\mathrm{P} \& 0$ và GA dò MPPT được chạy trên cấu hình tăng áp đề xuất. Qua hình nhận thấy rằng giải thuật GA dò ra được điểm có công suất cực đại là $127,1 \mathrm{~W}$, trong khi đó giải thuật $\mathrm{P} \& 0$ bị rơi vào điểm cực trị địa phương ở giữa là 108,1 W.

Trường hợp 3: Các tấm pin có mức bức xạ lần lượt là $800-400-200 \mathrm{~W} / \mathrm{m}^{2}$ (điểm cực đại toàn cục nằm ở giữa).

Hình 14 thể hiện đặc tuyến P-V của hệ thống pin quang điện với mức bức xạ lần lượt trên các module là $800-400-200 \mathrm{~W} / \mathrm{m}^{2}$, do đó đặc tuyến có 3 đỉnh công suất cực đại nhưng đỉnh có công suất lớn nhất là $55,79 \mathrm{~W}$ nằm ở giữa. Hình 15 lần lượt thể hiện điểm công suất mà giải thuật $P \& O$ và GA dò được chạy trên cấu hình tăng áp đề xuất. Qua hình nhận thấy rằng giải thuật GA dò ra được điểm có công suất cực đại là 55,82 W, trong khi đó giải thuật $\mathrm{P} \& \mathrm{O}$ bị rơi vào điểm cực trị địa phương ở bên trái là $50,98 \mathrm{~W}$.

Trường hợp 4: Các tấm pin có mức bức xạ lần lượt là $1.000-200-300 \mathrm{~W} / \mathrm{m}^{2}$ (điểm cực đại toàn cục nằm bên trái

Hình 16 thể hiện đặc tuyến P-V của hệ thống pin quang điện với mức bức xạ lần lượt trên các module là $1.000-200-300 \mathrm{~W} / \mathrm{m}^{2}$, do đó đặc tuyến có 3 đỉnh công suất cực đại nhưng đỉnh có công suất lớn nhất là 63,62 W nằm ở phía bên trái. Hình 17 lần lượt thể hiện điểm công suất mà giải 


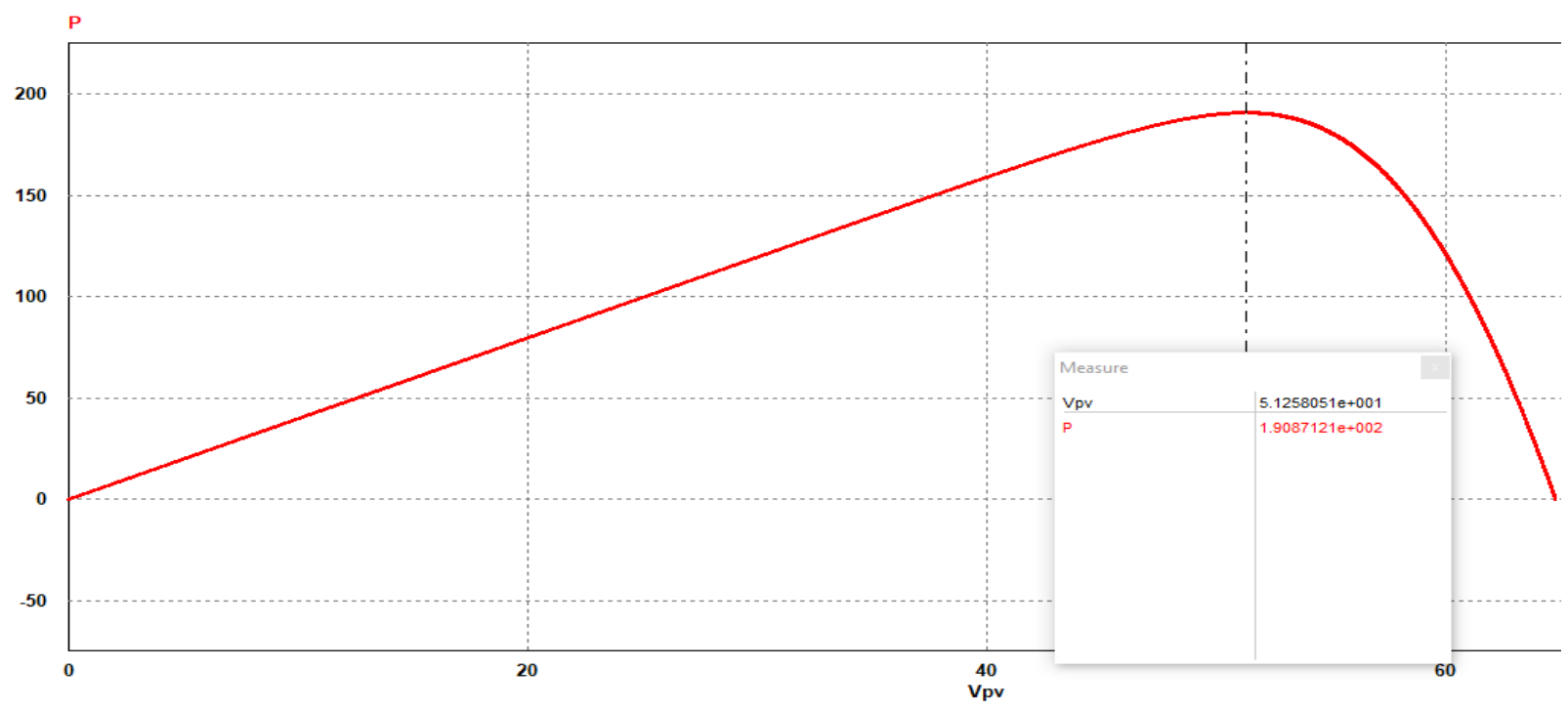

Hình 10. Đặc tuyến P-V của hệ thống pin quang điện 1000-1000-1000 W/m².

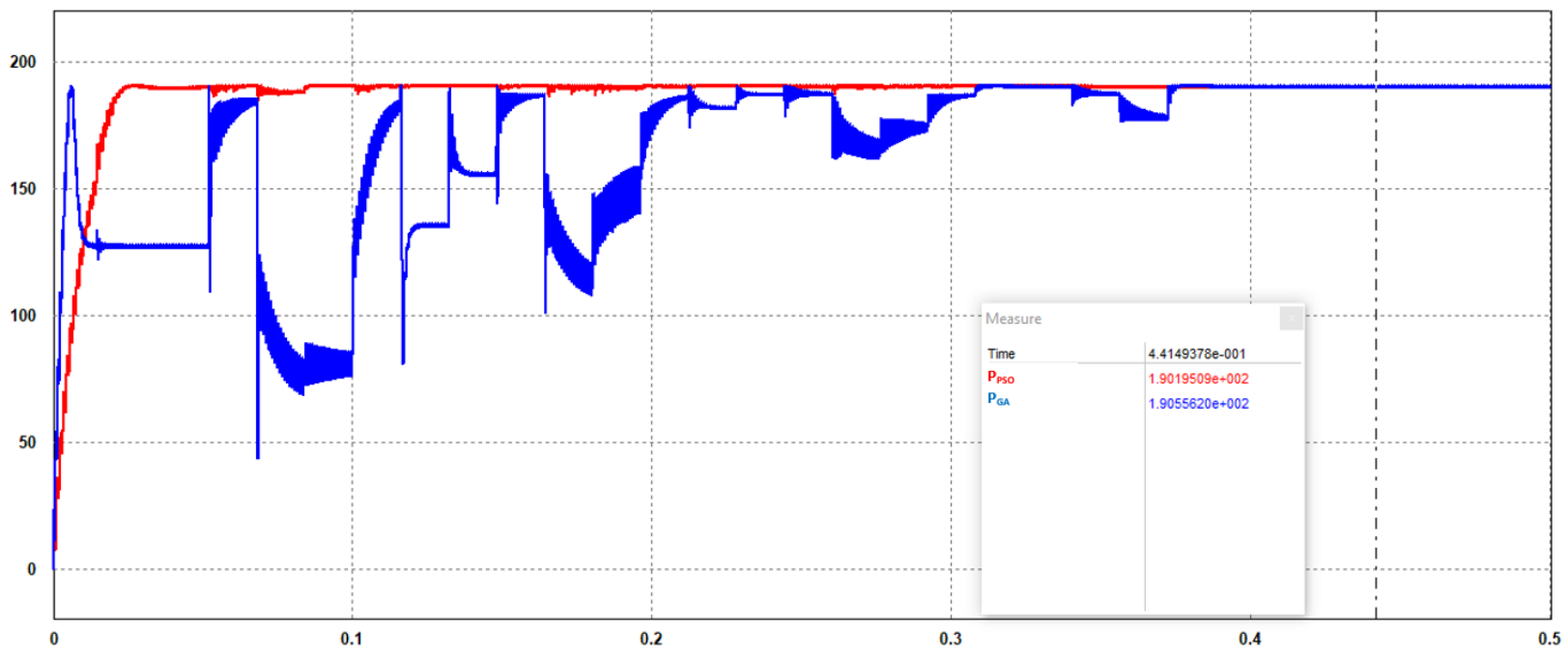

Hình 11. Kết quả mô phỏng dò điểm MPPT với giải thuật P\&O và GA 1000-1000-1000 W/m².

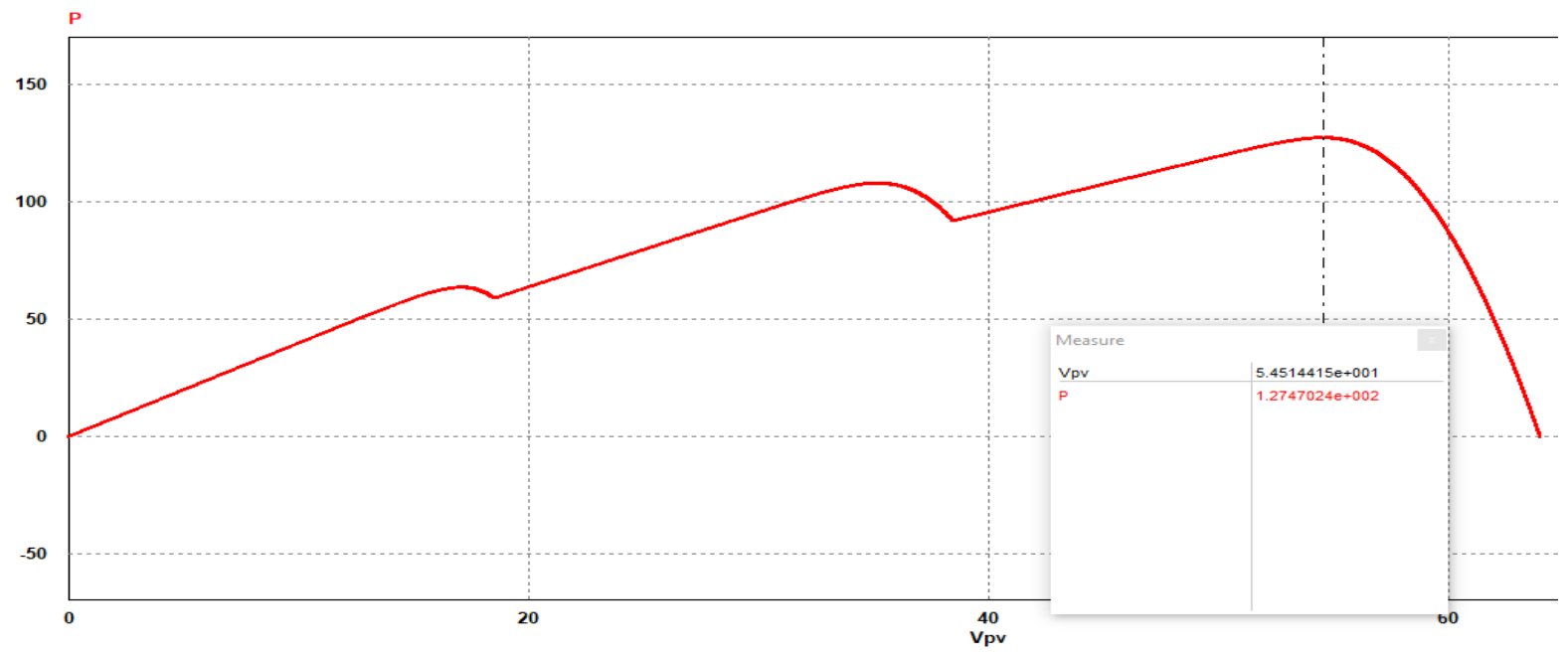

Hình 12. Đặc tuyến P-V của hệ thống pin quang điện 1000-800-600 W/m². 


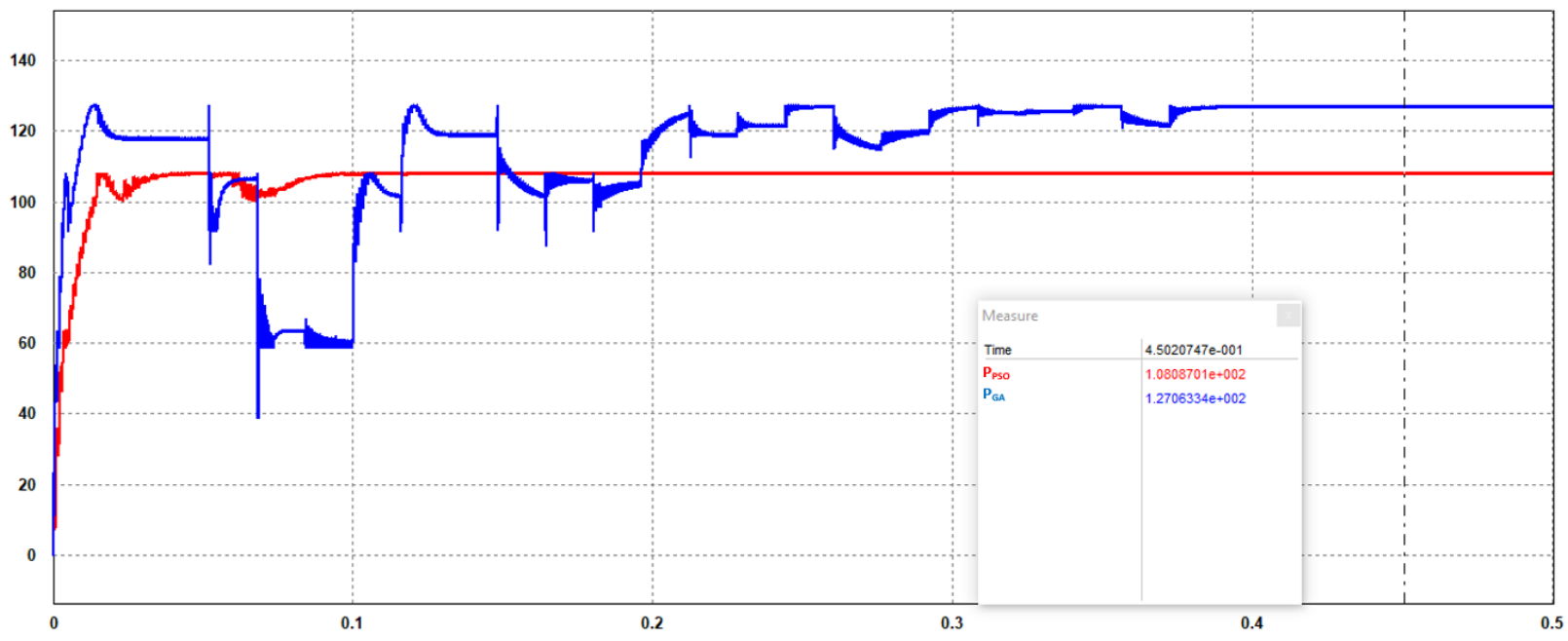

Hình 13. Kết quả mô phỏng dò điểm MPPT với giải thuật P\&O và GA 1000-800-600 W/m².

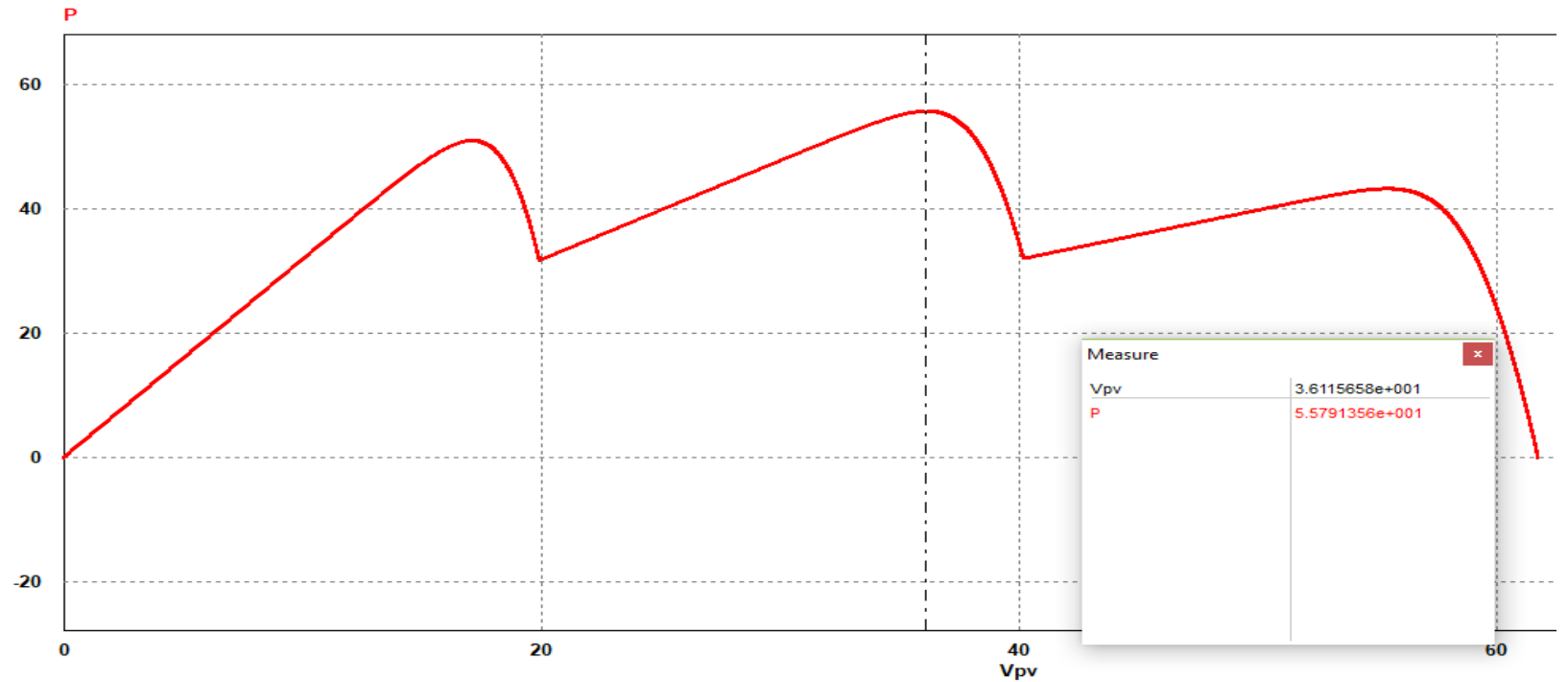

Hình 14. Đặc tuyến P-V của hệ thống pin quang điện 800-400-200 W/m².

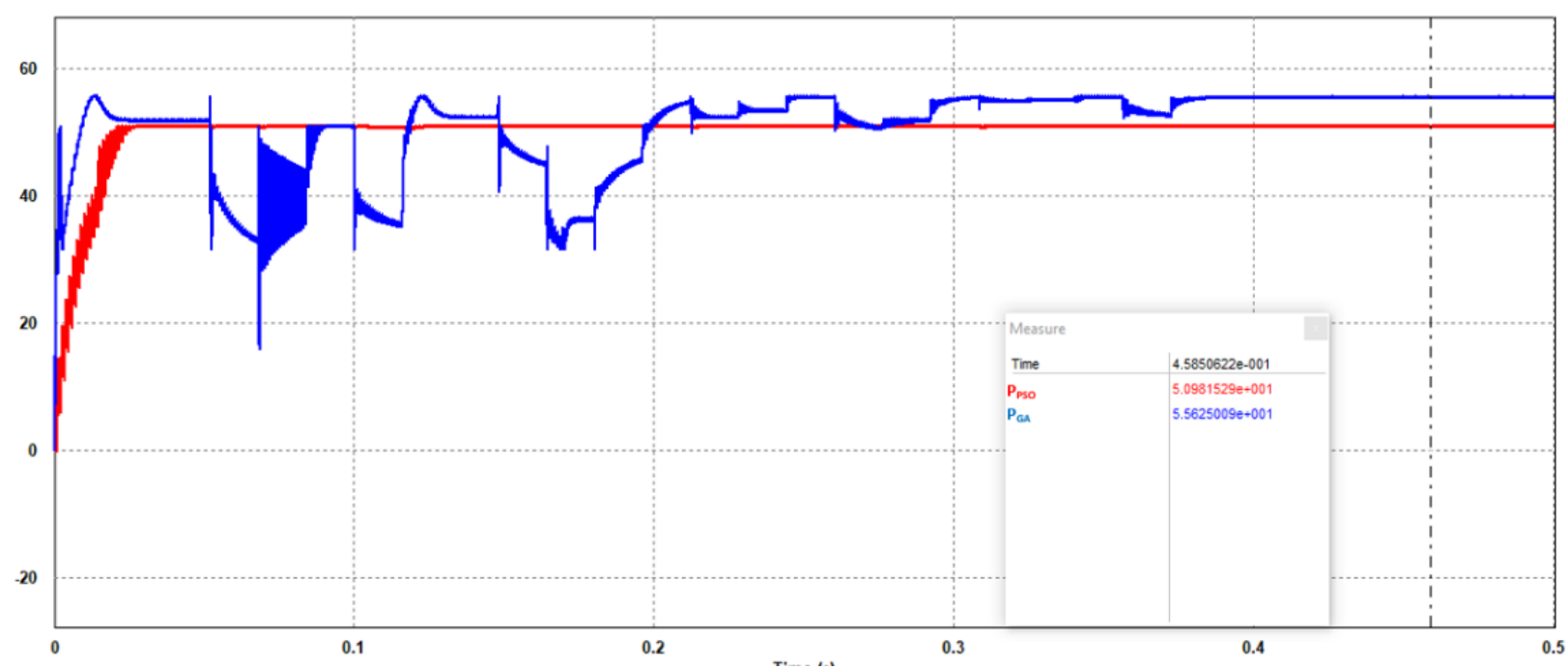

Hình 15. Kết quả mô phỏng dò điểm MPPT với giải thuật P\&O và GA 800-400-200 W/m². 


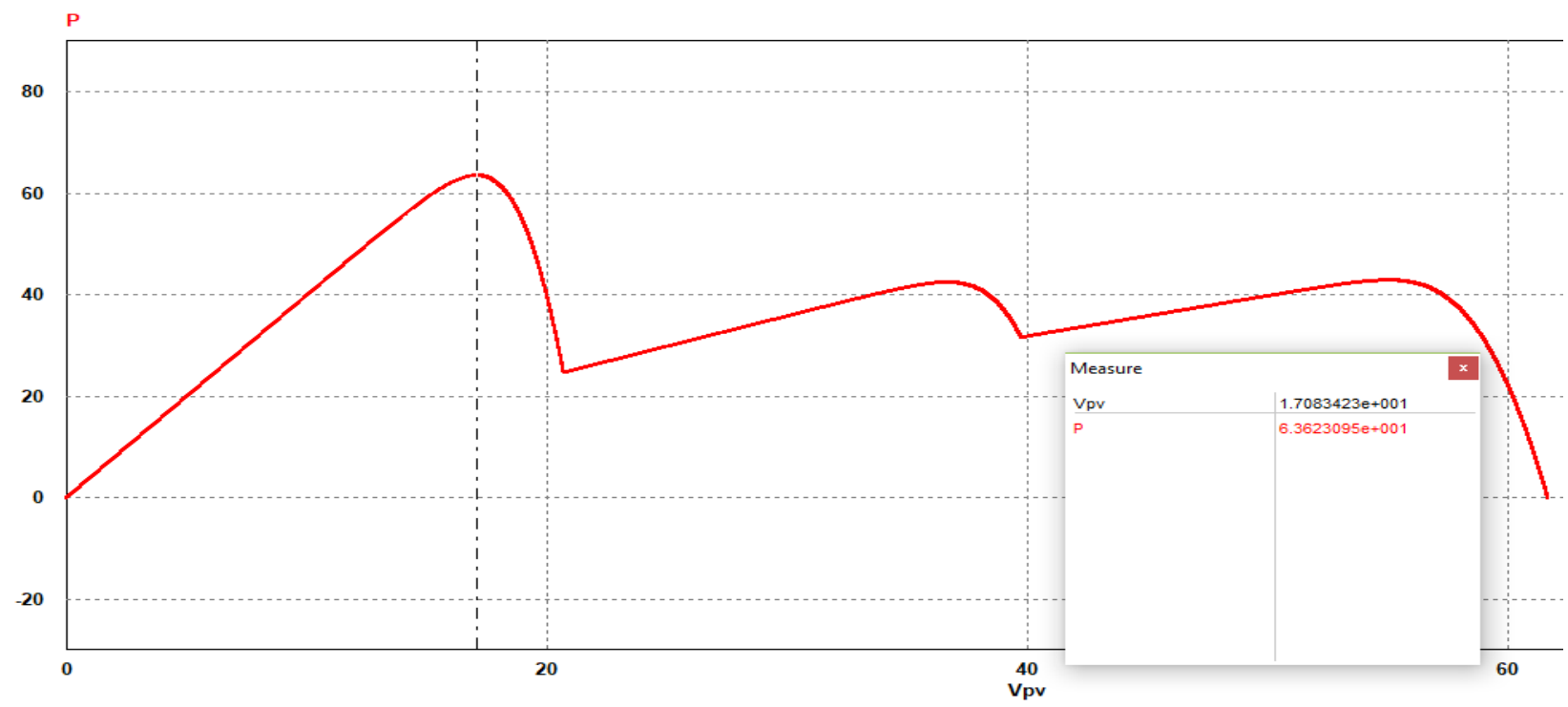

Hình 16. Đặc tuyến P-V của hệ thống pin quang điện 1.000 - $200-300 \mathrm{~W} / \mathrm{m}^{2}$.

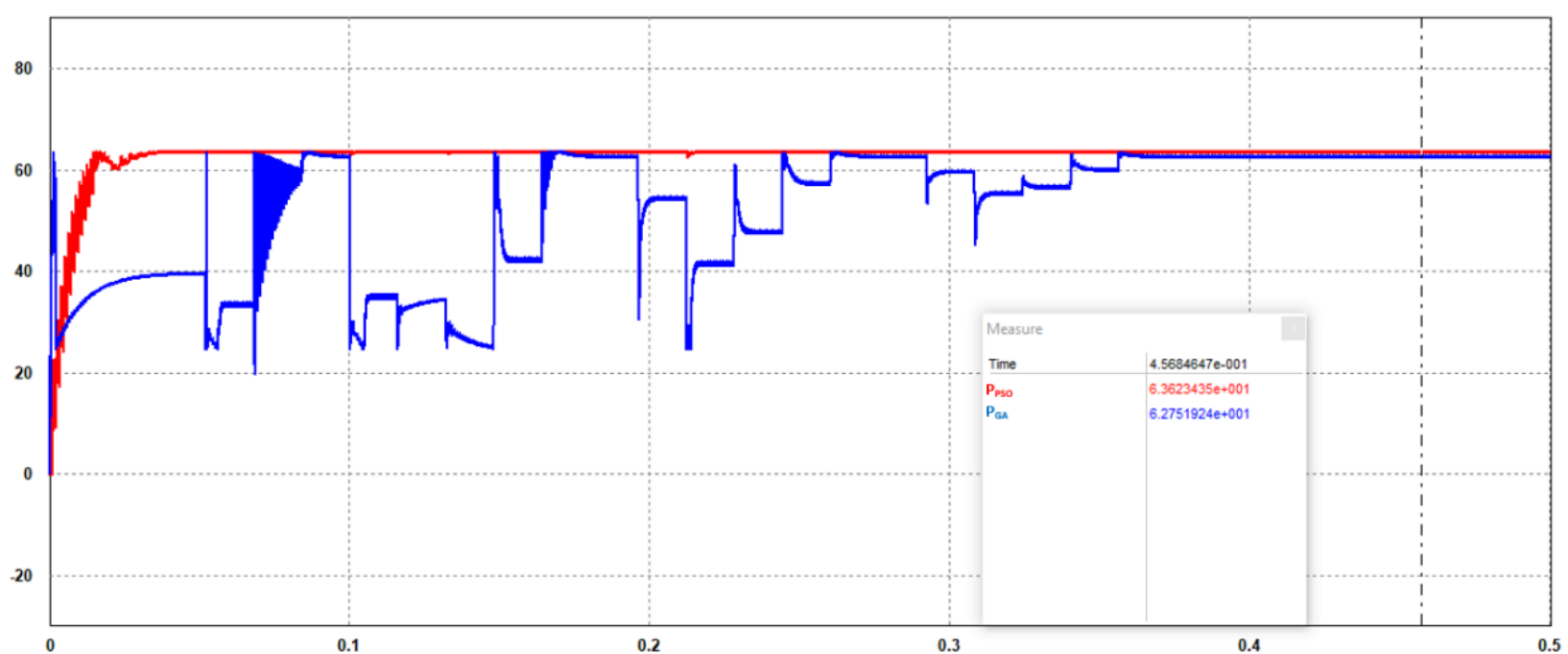

Hình 17. Kết quả mô phỏng dò MPPT với giải thuật P\&O, GA 1000-200-300 W/m².

thuật $P \& O$ và GA dò được chạy trên cấu hình tăng áp đề xuất. Qua hình 18 nhận thấy: cả 2 giải thuật đều dò ra điểm có công suất cực đại. Trong trường hợp này do điểm bức xạ nằm phía bên trái, bên cạnh đó hệ số chu kỳ $(\mathrm{D})$ lúc khởi động nằm gần điểm này nên vô tình giải thuật $\mathrm{P} \& O$ dò ra được. Nhưng trong thực tế đa số các đỉnh có công suất cực đại thường nằm bên phải hoặc ở giữa, nên sử dụng giải thuật $\mathrm{P} \& 0$ để dò điểm công suất cực đại trong hệ thống pin quang điện làm việc trong điều kiện có bóng che từng phần là không hiệu quả bằng giải thuật $\mathrm{GA}$.

\section{Kết luận}

Bài báo đã đề xuất một cấu hình tăng áp DC/DC giúp giảm số linh kiện bán dẫn, hệ số nhân áp cao, hiệu suất cao so với cấu hình truyền thống đã được nghiên cứu trước đó. Ngoài ra, cấu hình có cấu trúc đơn giản nên dễ dàng kiểm tra hư hỏng và xác suất hư hỏng trên các linh kiện thấp. Bài báo đã trình bày phương pháp điều chế độ rộng xung, nguyên lý hoạt động, kết quả phân tích mạch và tính toán, lựa chọn linh kiện cho cấu hình tăng áp $\mathrm{DC} / \mathrm{DC}$ đề xuất và áp dụng giải thuật dò điểm công suất cực đại trên cấu hình đề xuất. Trên cơ sở lý 
thuyết đã được trình bày, mô phỏng và thực nghiệm đã được tiến hành để chứng minh khả năng hoạt động của mạch. Từ kết quả mô phỏng và thực nghiệm đã kiểm chứng được một số ưu điểm của mạch tăng áp DC/DC đề xuất:

- Hệ số nhân áp cao: số lượng khóa bán dẫn giảm đáng kể so với các cấu hình đã nghiên cứu trước đó. Những ưu điểm của cấu hình đề xuất vượt trội hơn các cấu hình đã nghiên cứu trước đó: giảm sự phức tạp trong điều khiển do chỉ có một khóa bán dẫn; tiết kiệm chi phí; kích thước mạch nhỏ gọn.

- Hai giải thuật dò điểm công suất cực đại P\&O và GA khảo sát với hệ thống PV làm việc trong điều kiện có bóng che và không có bóng che chạy ổn định trên cấu hình đề xuất.

Bên cạnh đó, cấu hình tăng áp DC/DC có trung tính đề xuất là cần thiết và phù hợp cho các bộ nghịch lưu 3 bậc hình T và NPC, đáp ứng được các yêu cầu của các hệ thống PV công suất nhỏ quy mô hộ gia đình và công suất lớn nối lưới.

\section{Đóng góp của các tác giả}

Tác giả Nguyễn Đức Minh: đưa ra ý tưởng viết, thu thập dữ liệu, xây dựng giải thuật và đề xuất một cấu hình tăng áp cho nội dung bài viết. Trương Việt Anh: thiết kế, xây dựng mạch điều khiển cho mô hình thực nghiệm, giải thích các dữ liệu và thông số kỹ thuật. Lê Hoàng Phi: thiết kế, xây dựng mạch điều khiển cho mô hình thực nghiệm. Vũ Thị Thùy Lan: kiểm tra thông số thực nghiệm và xây dựng mô hình mô phỏng. Đỗ Như Ý: mô phỏng và kiểm tra các thông số thực nghiệm và hiệu chỉnh hình thức tổng quan bài viết. Trịnh Trọng Chưởng: thực nghiệm, mô phỏng so sánh đưa ra kết luận và kiểm tra hiệu chỉnh nội dung bài viết.

\section{Tài liệu tham khảo}

Figueres, E., Garceras, G., Sandia, J., Espisn, F. G., and Rubio, J. C. (2009). Sensitivity study of the dynamics of three-phase photovoltaic inverters with an LCL grid filter. IEEE Trans. Ind. Electron., 56(3), 706-717.

Deshpande, S., and Bhasme N. R. (2018). A review of topologies of inverter for grid connected PV systems. 2017 Innov. Power Adv. Comput.

Technol. i-PACT 2017, 2017-Janua, 1-6.

Selvaraj, J., and Rahim, N. A. (2009). Multilevel Inverter For Grid-ConnectedPV System Employing Digital PI Controller. IEEE Trans. Ind. Electron., 56(1), 149-158.

Scarpa, V.V. R., Buso, S., and Spiazzi, G. (2009). Lowcomplexity MPPT technique exploiting the PV module MPP locus characterization. IEEE Trans. Ind. Electron., 56(5), 1531-1538.

Li, W., Liu, J., Wu, J., and He, X. (2007). Design and analysis of isolated ZVT boost converters for highefficiency and high-step-up applications. IEEE Trans. Power Electron., 22(6), 23632374.

Sahoo, M., and Kumar, K. S. (2014). High gain step up DC-DC converter for DC micro-grid application. 2014 7th Int. Conf. Inf. Autom. Sustain. "Sharpening Futur. with Sustain. Technol. ICIAfS 2014.

Chen, S., Zhou, L., Luo, Q., and Zhu, B. (2013). Interleaved non-isolated high step-up DC/ DC converter based on the diodecapacitor multiplier. IET Power Electron., 7(2), 390-397.

Marabeas, P., Coutellier, D., Yang, J., Choi, S., and Agelidis, V. G. (2011). Analysis, design and experimental results of a floatingoutput interleaved-input boost-derived DCDC high-gain transformer-less converter. IET Power Electron., 4(1), 168.

Das, D., and Pradhan, S. K. P. (2011). Modeling and Simulation of PV Array With Boost Converter : An Open Loop Study. pp. 1-47.

Khan, A., and Pal, S. (2017). Study PV Module Characteristics. Int. Conf. Energy, Commun. Data Anal.Soft Comput., 3, 2399-2403.

Kumari J. S., and Babu, C. S. (2013). Mathematical Modeling and Simulation of Photovoltaic Cell using Matlab-Simulink Environment. Int. J. Electr. Comput. Eng., 2(1), 26-34.

Armstrong, M., Atkinson, D. J., Johnson, C. M., and Abeyasekera, T. D. (2006). Auto-calibrating dc link current sensing technique for transformerless, grid connected, H-bridge inverter systems. IEEE Trans. Power Electron., 21(5), 1385-1393. 